\title{
Editorial
}

\section{Une opportunité à saisir}

Comme annoncé déjà dans le précédent numéro d'Andrologie, le XXIIIème Congrès d la SALF sera réduit à demi journée et adossé au 4ème Congrès de l'EAA (European Academy of Andrology) organisé à Toulouse du 7 au 10 décembre 2006. Ce Congrès sera précédé du 4ème Workshop on epididymis organisé par Joël Drevet à Chatel-Guyon (4 au 7 décembre 2006) et soutenu par la SALF.

Au cours de ce 4 ème Congrès de l'Académie Européenne d'Andrologie, une opportunité est à saisir pour toutes les équipes qui travaillent dans le vaste champ de l'andrologie. En effet, quatre sessions plénières de communications orales se dérouleront, qui porteront sur des thèmes couvrant tout le champs de l'Andrologie.

Chaque session durera une heure et demie et permettra à 6 à 9 intervenants sélectionnés de présenter leurs travaux en 10 à 15 minutes (incluant la discussion) en session plénière. Au total, cette organisation du congrès offre de 24 à 36 communications orales.

La sélection sur laquelle repose l'accès à une communication libre est simple : un appel a présenter des résumés (en anglais) est ouverte jusqu'au 14 juillet 2006. Lors du précédent congrès de l'EAA, 250 résumés ont été proposés. A partir de ces propositions, le comité de sélection, composé des membres du POC (Program Organizing Committee), a classé les abstracts en communication libre ou poster.

A chaque équipe de saisir cette opportunité de présenter ses travaux les plus récents, orignaux ou pertinents en session plénière lors de ce congrès.

Roger Mieusset 